\section{Fluoride intake of infants living in non-fluoridated and fluoridated areas}

\author{
F. V. Zohoori, ${ }^{* 1}$ G. Whaley, ${ }^{1}$ P. J. Moynihan ${ }^{2,3,4}$ and A. Maguire ${ }^{2}$ \\ VERIFIABLE CPD PAPER
}

IN BRIEF
- Highlights the large impact that the
fluoride content of drinking water has
on the total daily fluoride intake of very
young children.
- Illustrates that diet is the only source of
fluoride intake for most infants.
- Stresses the need for dental
professionals to evaluate the daily
fluoride intake of their young
child patients before making any
recommendations for fluoride use.

\begin{abstract}
Objectives Data on fluoride exposure of infants are sparse. This study aimed to estimate total daily fluoride intake (TDFI) of infants aged 1-12 months, living in non-fluoridated and fluoridated areas in north-east England. Methods Daily dietary fluoride intake was assessed using a three-day food diary coupled with analysis of fluoride content of food/ drink consumed, using a F-ISE and diffusion method. A questionnaire with an interview was used to collect information on toothbrushing habits. TDFI was estimated from diet, plus fluoride supplements and dentifrice ingestion where used. Results Thirty-eight infants completed the study; 19 receiving fluoridated water (mean $0.97 \mathrm{mgF} /$ ) and 19 receiving non-fluoridated water (mean $0.19 \mathrm{mgF} / \mathrm{I}$ ). Mean (SD) TDFI for the infants living in fluoridated and non-fluoridated areas was 0.107 (0.054) and 0.024 (0.015) $\mathrm{mg} / \mathrm{kg}$ body weight per day, respectively. Diet was the only fluoride source for $87 \%$ of infants and none used fluoride supplements. For infants for whom mouth/teeth cleaning was undertaken, dentifrice contribution to TDFI ranged from 24 to 78\%. Conclusions Infants living in fluoridated areas, in general, may receive a fluoride intake, from diet only, of more than the suggested optimal range for TDFI. This emphasises the importance of estimating TDFI at an individual level when recommendations for fluoride use are being considered.
\end{abstract}

\section{INTRODUCTION}

Despite being largely preventable, dental caries is still one of the most common chronic diseases in children. The role of fluoride $(\mathrm{F})$ in preventing and controlling dental caries is well established. Evidence suggests that the predominant caries-preventive effects of $F$ occur through its topical rather than systemic effect. ${ }^{1}$ Topical oral exposure to low levels of $\mathrm{F}$ helps prevent demineralisation and promote remineralisation of early carious lesions. However, chronic excessive systemic F intake from birth to four years of age is considered to be a key contributor to dental fluorosis development in permanent maxillary central incisors. ${ }^{2,3}$ Furthermore, Levy et $a l .{ }^{4}$ has suggested that the sixnine-month-old period is most important in dental fluorosis aetiology for the primary dentition, while Warren et al. ${ }^{5}$ determined that the critical period for development of

1School of Health and Social Care, Teesside University; ${ }^{2}$ Centre for Oral Health Research, 3 Institute for Ageing and Health, ${ }^{4}$ Human Nutrition Research Centre, Newcastle University

${ }^{*}$ Correspondence to: Dr Vida Zohoori

Email: v.zohoori@tees.ac.uk; Tel: 01642342973

Online article number E3

Refereed Paper - accepted 25 September 2013

DOI: 10.1038/sj.bdj.2014.35

${ }^{\circ}$ British Dental Journal 2014; 216: E3 fluorosis in late developing primary teeth is from four months in utero until 11 months of age. Hence, children can be at risk of dental fluorosis in both dentitions depending on time and period of excessive systemic exposure to F. It is, therefore, important to control F intake, especially during enamel formation, to reduce the risk of dental fluorosis and this applies to both the primary and permanent dentitions.

Although there is no consensus on the maximum safe daily intake of $\mathrm{F}$, a total F intake of 0.05-0.07 mg/kg body weight per day (mg/kg BW per d), in children younger than 12 years of age, is regarded as optimum for dental health benefits. ${ }^{6}$ It is also generally agreed that intakes of F should not exceed a tolerable upper intake level (UL) of $0.1 \mathrm{mg} / \mathrm{kg}$ BW per d, during infancy, to minimise the risk of dental fluorosis. ${ }^{6}$

Dental fluorosis has been reported to be more prevalent in the permanent teeth of children who had been fed powdered infant milk formula diluted with the local fluoridated water supply during the first four months of life than in those who had been breast-fed., However, the Iowa F Study recognises total F intake as the true risk factor for dental fluorosis $^{9}$ and in infants this is dependent on their feeding patterns, F concentrations of infant milk formula and weaning foods/drinks, dentifrice usage and their toothbrushing habits.

Several studies in fluoridated areas, mainly conducted in North America in 1970s, estimated that daily F intakes of some infants were above the upper threshold of $0.07 \mathrm{mg} / \mathrm{kg} / \mathrm{d} .{ }^{10-12}$ Consequently, infant formula manufacturers decided voluntarily to use non-fluoridated water in their products in response to a concern about dental fluorosis. However, recent studies ${ }^{13,14}$ have shown a greater impact of the F content of water used to reconstitute infant powdered formula on $F$ intake of formula-fed infants than the F content of the powdered formula itself. Furthermore, most recently there have been trends towards a greater use of ready-to-feed infant products due to their convenience. Recent studies in the $\mathrm{UK}^{14,15}$ have also shown some infant products to contain a relatively high concentration of F (for example, ready-to-feed meat-based weaning foods have been found to have a F concentration of up to $1.20 \mu \mathrm{g} / \mathrm{g})$. Despite the importance of monitoring $\mathrm{F}$ exposure in infancy due to the potential bidirectional correlation between $\mathrm{F}$ exposure and oral health (that is, caries prevention and dental fluorosis), to date there has been no study of total $\mathrm{F}$ ingestion in this age group in the 
UK. This study aimed to estimate total daily F intake of infants living in non-fluoridated and fluoridated areas in the UK to provide current data on $\mathrm{F}$ exposure in infancy that reflect current dietary practice.

\section{MATERIAL AND METHODS}

This study was conducted according to the guidelines laid down in the Declaration of Helsinki and all procedures involving human subjects/patients were approved by the School of Health and Social Care, Teesside University Ethics Committee (Ethics number: 059/10) and the Faculty of Medical Sciences Ethic Committee, Newcastle University (Ethics number: Case 000311).

The study was undertaken in fluoridated and non-fluoridated areas of north-east England. Parents of healthy infants aged 1-12 months who were lifelong residents of the area were contacted. Informed written consent was obtained from the 40 parents who volunteered to take part in the study: 20 from an artificially fluoridated area and 20 from a non-fluoridated area.

The weights of the infants, with light clothes, were measured to the nearest $0.1 \mathrm{~kg}$ using a portable digital baby scale (Learning Curve Brands Inc., UK).

The dietary $\mathrm{F}$ intake of the infants was estimated using a three-day food-diary on three consecutive days - two weekdays and one weekend day. ${ }^{16} \mathrm{~A}$ diary was given to each parent with verbal and written instructions on how to complete the fooddiary for their infant. Each parent was interviewed on the fourth day to ensure that all food and drink items consumed by their infant had been recorded and samples of all food and drink, including breast-milk, consumed by the infants during the threeday dietary assessment were collected. In breast-fed infants, consumption of breastmilk was quantified from reported energy requirements, by age and gender, of breastfed infants ${ }^{17}$ and the average caloric density of human milk of $651 \mathrm{kcal} / 1 .^{18}$

F concentrations of food and milk samples were measured after overnight diffusion using a F ion-specific electrode. ${ }^{19,20}$ Fluoride concentrations of water and other drink samples were measured directly after adding total ionic strength adjustment buffer, using a F ion-selective electrode. ${ }^{15}$ For each infant the daily dietary $F$ intake $(\mathrm{mg} / \mathrm{d})$ from each individual food/drink item was then estimated by multiplying the intake of the item $(\mathrm{g} / \mathrm{d})$ by its $\mathrm{F}$ concentration $(\mathrm{mg} / \mathrm{g})$.

Information on the infant's toothbrushing was obtained using a parental questionnaire and face-to-face questioning. In the case of dentifrice use, the frequency of cleaning/brushing, type and amount of

Table 1 Median, minimum and maximum age (months) and weight $(\mathrm{kg})$ of infants residing in fluoridated-water and non-fluoridated-water areas

\begin{tabular}{|c|c|c|c|c|c|c|c|}
\hline & \multirow[t]{2}{*}{ No. } & \multicolumn{3}{|c|}{ Age (months) } & \multicolumn{3}{|c|}{ Weight (kg) } \\
\hline & & Median & Min & Max & Median & Min & Max \\
\hline \multicolumn{8}{|c|}{ Fluoridated-water area $(0.97 \mathrm{mgF} / \mathrm{l})$} \\
\hline All infants & 19 & 3.3 & 0.8 & 12.5 & 5.9 & 3.0 & 11.6 \\
\hline Infants with no brushing habits & 17 & 3.2 & 0.8 & 11.8 & 5.8 & 3.0 & 11.6 \\
\hline Infants with brushing habits & 2 & 12.3 & 12.0 & 12.5 & 10.6 & 10.2 & 11.0 \\
\hline \multicolumn{8}{|c|}{ Non-fluoridated-water area $(0.19 \mathrm{mgF} / \mathrm{l})$} \\
\hline All infants & 19 & 3.0 & 1.2 & 12.0 & 5.4 & 4.3 & 11.8 \\
\hline Infants with no brushing habits & 16 & 2.4 & 1.2 & 11.5 & 5.1 & 4.3 & 10.0 \\
\hline Infants with brushing habits & 3 & 11.2 & 10.0 & 12.0 & 10.4 & 9.1 & 11.8 \\
\hline All infants from both areas & 38 & 3.2 & 0.8 & 12.5 & 5.8 & 3.0 & 11.8 \\
\hline
\end{tabular}

dentifrice used and time of brushing were recorded. The amount of $\mathrm{F}$ ingested through brushing was estimated from the weight and frequency of dentifrice use, assuming almost all dentifrice used in brushing is swallowed by an infant at this age.

No infant used F supplements, therefore the total daily fluoride intake (TDFI) for each infant was calculated by combining $\mathrm{F}$ intake from diet and any dentifrice ingestion.

The data were analysed descriptively using SPSS version 17.0 (IBM).

\section{RESULTS}

In total, 38 infants completed the study; 19 from each area. The mean (SD) $F$ concentrations of home supply water in the fluoridated and non-fluoridated areas were $0.97(0.13)$ and $0.19(0.10) \mathrm{mg} / \mathrm{l}$, respectively.

More than 70\% of infants were less than six months and of those, 50\% were less than three months of age at the time of the study. The median age of infants was 3.3 months in fluoridated areas and 3.0 months in nonfluoridated areas (Table 1). The median weights of infants in the fluoridated and non-fluoridated areas were 5.9 and $5.4 \mathrm{~kg}$, respectively (Table 1).

Only four infants were exclusively breastfed: one in the fluoridated area and three in the non-fluoridated area. Overall, 89\% and $84 \%$ of infants in the fluoridated and nonfluoridated areas, respectively, were fed with infant powdered formula milk, prepared with home tap water, either exclusively or as part of their whole diet. The proportions of weaned infants were similar (21\%) in both areas.

The overall mean (SD) TDFI for all infants living in the fluoridated $(n=19)$ and non-fluoridated $(\mathrm{n}=19)$ areas was 0.107 (0.054) and $0.024(0.015) \mathrm{mg} / \mathrm{kg}$ BW per $\mathrm{d}$, respectively. The mean $(\mathrm{SD})$ dietary $\mathrm{F}$ intake for those living in the fluoridated and non-fluoridated areas was $0.103(0.057)$ and $0.021(0.012) \mathrm{mg} / \mathrm{kg}$ BW per d, respectively.

Diet was the only source of $F$ intake for 33 infants; 17 in the fluoridated and 16 in the non-fluoridated areas. The median (range) TDFI of the infants without habitual toothbrushing was $0.136(0.003,0.181) \mathrm{mg} /$ $\mathrm{kg}$ BW per $\mathrm{d}$ in the fluoridated area and $0.024(0.003,0.042) \mathrm{mg} / \mathrm{kg}$ BW per $\mathrm{d}$ in the non-fluoridated area (Table 2). F intake of weaned infants without habitual toothbrushing was slightly lower than that of non-weaned infants in both areas. Infant milk formula was the main source of F intake for the infants without toothbrushing habits; whereas for infants in whom mouth/teeth cleaning was undertaken, the mean F intake from toothpaste ingestion was the main source of F intake (Table 3). F intake from toothpaste ingestion contributed to up to $78 \%$ of TDFI for those infants with habitual toothbrushing.

There was an inverse relationship between age and TDFI for those infants living in the fluoridated area, whereas a positive trend in the relationship between age and TDFI was observed for the infants living in the nonfluoridated area (Fig. 1).

Only 5\% of infants living in the nonfluoridated area had a TDFI within the so called 'optimal' range of 0.05-0.07 mg/kg BW per $\mathrm{d}$, while for the remaining infants it was less than $0.05 \mathrm{mg} / \mathrm{kg} \mathrm{BW}$ per $\mathrm{d}$. In the fluoridated area, $21 \%$ of infants had a TDFI of less than $0.05 \mathrm{mg} / \mathrm{kg}$ BW per $\mathrm{d}$ whereas it was more than $0.10 \mathrm{mg} / \mathrm{kg}$ BW per $\mathrm{d}$ for $53 \%$ of infants living in the non-fluoridated area (Fig. 1).

\section{DISCUSSION}

The present paper is the furst report on total daily F intake of infants, from all sources, in 
Table 2 Median, minimum and maximum total daily fluoride intake (TDFI) of infants without toothbrushing habits residing in fluoridated areas (total $=17$, weaned $=4$, non-weaned $=13$ ) and non-fluoridated-water areas (total $=16$, weaned $=4$, non-weaned $=12$ )

\begin{tabular}{|c|c|c|c|c|c|c|c|c|c|}
\hline & \multicolumn{3}{|c|}{ All infants } & \multicolumn{3}{|c|}{ Weaned infants } & \multicolumn{3}{|c|}{ Non-weaned infants } \\
\hline & Median & Min & Max & Median & Min & $\operatorname{Max}$ & Median & Min & $\operatorname{Max}$ \\
\hline \multicolumn{10}{|c|}{ Fluoridated-water area $(0.97 \mathrm{mgF} / \mathrm{l})$} \\
\hline Age (months) & 3.0 & 0.7 & 10.9 & 10.0 & 4.1 & 10.9 & 2.8 & 0.7 & 3.7 \\
\hline \multicolumn{10}{|l|}{ Daily F intake from: } \\
\hline Milk, all types (mg/d) & 0.683 & 0 & 1.002 & 0.423 & 0 & 0.599 & 0.704 & 0.010 & 1.002 \\
\hline Other drinks (mg/d) & 0 & 0 & 0.029 & 0.021 & 0.005 & 0.029 & 0 & 0 & 0 \\
\hline Solid food (mg/d) & 0 & 0 & 0.180 & 0.112 & 0.033 & 0.180 & 0 & 0 & 0 \\
\hline \multicolumn{10}{|l|}{ Total daily F intake } \\
\hline$-\mathrm{mg} / \mathrm{d}$ & 0.683 & 0.010 & 1.002 & 0.564 & 0.170 & 0.661 & 0.703 & 0.010 & 1.002 \\
\hline - $\mathrm{mg} / \mathrm{kg} \mathrm{BW}^{*}$ per d & 0.136 & 0.003 & 0.181 & 0.060 & 0.015 & 0.095 & 0.140 & 0.003 & 0.181 \\
\hline
\end{tabular}

Non-fluoridated-water area $(0.19 \mathrm{mgF} / \mathrm{l})$

\begin{tabular}{|c|c|c|c|c|c|c|c|c|c|}
\hline Age (months) & 2.2 & 1.1 & 10.6 & 5.0 & 4.4 & 10.6 & 2.0 & 1.1 & 3.7 \\
\hline \multicolumn{10}{|l|}{ Daily F intake from: } \\
\hline Milk, all types (mg/d) & 0.102 & 0.014 & 0.210 & 0.092 & 0.065 & 0.106 & 0.130 & 0.014 & 0.210 \\
\hline Other drinks (mg/d) & 0 & 0 & 0.019 & 0.010 & 0.002 & 0.019 & 0 & 0 & 0 \\
\hline Solid food (mg/d) & 0 & 0 & 0.071 & 0.058 & 0.023 & 0.071 & 0 & 0 & 0 \\
\hline \multicolumn{10}{|l|}{ Total daily F intake } \\
\hline$-m g / d$ & 0.141 & 0.014 & 0.221 & 0.170 & 0.091 & 0.221 & 0.130 & 0.014 & 0.210 \\
\hline - $m g / k g B W^{*}$ per d & 0.024 & 0.003 & 0.042 & 0.020 & 0.018 & 0.030 & 0.027 & 0.003 & 0.042 \\
\hline
\end{tabular}

${ }^{*} \mathrm{BW}=$ body weight

Table 3 TDFI of five infants with toothbrushing habits residing in fluoridated-water and non-fluoridated-water areas

\begin{tabular}{|l|l|l|l|l|l|}
\hline & \multicolumn{5}{l}{ Infant } \\
\hline Area of residency & 1 & 2 & 3 & 4 & 5 \\
\hline Age (months) & $\mathrm{F}^{*}$ & $\mathrm{~F}^{*}$ & $\mathrm{NF}^{+}$ & $\mathrm{NF}^{+}$ & $\mathrm{NF}^{+}$ \\
\hline & 11.3 & 11.5 & 9.0 & 11.1 & 10.4 \\
\hline
\end{tabular}

Sources of $F$ intake:

\begin{tabular}{|l|l|l|l|l|l}
\hline Milk $(\mathrm{mg} / \mathrm{d})$ & 0.257 & 0.463 & 0.136 & 0.088 & 0.065 \\
\hline Other drinks $(\mathrm{mg} / \mathrm{d})$ & 0.036 & 0.046 & 0.021 & 0.001 & 0.004 \\
\hline Solid food $(\mathrm{mg} / \mathrm{d})$ & 0.178 & 0.133 & 0.073 & 0.053 & 0.119 \\
\hline Toothpaste $(\mathrm{mg} / \mathrm{d})$ & 0.500 & 0.200 & 0.201 & 0.500 & 0.100 \\
\hline
\end{tabular}

Total daily F intake (TDFI):

\begin{tabular}{|c|c|c|c|c|c|}
\hline $\mathrm{mg} /$ day & 0.972 & 0.841 & 0.430 & 0.642 & 0.288 \\
\hline $\mathrm{mg} / \mathrm{kg} \mathrm{BW}^{* *}$ per d & 0.095 & 0.076 & 0.047 & 0.054 & 0.028 \\
\hline $\mathrm{F}$ in toothpaste as proportion of TDFI (\%) & 51 & 24 & 46 & 78 & 35 \\
\hline
\end{tabular}

the first year of life, in the UK. This is also the first study in which a detailed assessment of dietary $\mathrm{F}$ intake over three days was undertaken using a three-day food-diary with interview method together with an analysis of $\mathrm{F}$ content of both ready-tofeed and home-made food/drink items actually consumed by infants. This study is also unique in that it estimated $\mathrm{F}$ intake of breast-fed infants and has indicated that diet was the only source of $F$ intake for the infants up to the age of nine months in both fluoridated and non-fluoridated areas and the predominant source of $F$ until the age of 12 months in the fluoridated area.

The compatibility of the UK infant dietary guidelines with those of the European Society for Paediatric Gastroenterology, Hepatology and Nutrition's Committee on Nutrition ${ }^{21}$ for the European region implies similar infant feeding patterns in the UK and other European countries. In addition, the food/drink items consumed by infants in the present study were manufactured by the leading companies in the European baby food market. ${ }^{14,15}$ Therefore, the findings of this study on dietary F intake of infants are relevant to other European countries with similar exposures to fluoridation (that is, similar F concentrations in fluoridated water supplies or salt).

In the present study, the observed positive trend between a child's age and TDFI for those living in the non-fluoridated area could be mainly due to the increasing use of fluoridated dentifrice in the older (9- to 12-month-old) children. On the other hand, the inverse relationship between age and TDFI for the infants living in the fluoridated area may have been due to decreased $F$ intake from reconstituted infant formula and the introduction of weaning foods/drinks containing less $\mathrm{F}$ with age. A trend towards a decline in TDFI from $0.074 \mathrm{mg} / \mathrm{kg}$ BW per $\mathrm{d}$ at 1.5 months of age to $0.036 \mathrm{mg} / \mathrm{kg} \mathrm{BW}$ per $d$ at 12 months of age was also reported in Iowa-US in $2001 .^{22}$

Cressey $^{13}$ used a stochastic model to estimate the dietary $F$ intake of fully formula-fed infants in New Zealand. Based on an average prepared infant milk formula F concentration of $0.76 \mathrm{mg} / \mathrm{l}$, the dietary $\mathrm{F}$ intake was estimated to be $0.11 \mathrm{mg} / \mathrm{kg}$ BW per d. Using the same stochastic approach, an average dietary $\mathrm{F}$ intake of $0.132 \mathrm{mg} /$ kg BW per d was estimated for exclusively formula-fed infants in Ireland, if the prepared formula $\mathrm{F}$ concentration was $0.84 \mathrm{mg} / \mathrm{l}^{23}$ The mean dietary $F$ intake of $0.103 \mathrm{mg} / \mathrm{kg}$ BW per d obtained in the present study was slightly lower than the hypothetical estimates of dietary $\mathrm{F}$ intake for infant reported by these two latter studies in New Zealand and Ireland. However, the median dietary F intake of $0.683 \mathrm{mg} / \mathrm{d}$ (range: 0.010 to $1.002 \mathrm{mg} / \mathrm{d}$ ) found for infants without tooth brushing habits living in fluoridated area, in the present study, was higher than the corresponding values of $0.330 \mathrm{mg} / \mathrm{d}$ (rang: 0.005 to $2.076 \mathrm{mg} / \mathrm{d}$ ) and $0.407 \mathrm{mg} / \mathrm{d}$ (range: 0.011 to $1.900 \mathrm{mg} / \mathrm{d}$ ) reported for six- and 
nine-month-old infants, respectively, living in Iowa, United States. ${ }^{24}$

Most previous $\mathrm{F}$ intake studies in infants have focused on intake of $F$ mainly from drinks (including infant milk formula). The mean contribution of 35\% of dietary F from solid foods obtained for weaned infants in the present study was in agreement with the corresponding contribution of 39\% reported for 12-month-old infants in Iowa-US. ${ }^{24}$ However, the present study showed that the contribution of solid foods to total dietary $\mathrm{F}$ intake could be up to $89 \%$ in weaned infants.

Epidemiological surveys in the UK have shown evidence of dental caries experience in $39 \%$ of five-year-olds ${ }^{25}$ while $33 \%$ of 11 -year-olds ${ }^{26}$ have dental caries. Dental fluorosis prevalence (at any severity level) of 55\% in fluoridated areas and $27 \%$ in non-fluoridated areas ${ }^{27}$ have been reported, although for dental fluorosis of aesthetic concern the prevalence was 7.1\% in fluoridated areas and 1.2\% in nonfluoridated areas. Although the proportions of infants receiving formula feeds were similar at 89\% in fluoridated and 84\% in non-fluoridated areas, in the present study, the TDFI of almost 79\% of the infants living in the fluoridated area exceeded the F intake threshold of $0.07 \mathrm{mg} / \mathrm{kg}$ BW per $d$, while TDFI of 95\% of infants living in non-fluoridated areas were below the lower threshold of the suggested 'optimal' $F$ intake $(0.05 \mathrm{mg} / \mathrm{kg}$ BW per d). The findings of this F intake study of infant are of importance since 55\% of newborns in the UK are fed with infant formula reconstituted with water: this proportion increases to $93 \%$ at four months and almost $100 \%$ at six months. ${ }^{28}$

The longitudinal Iowa F study ${ }^{9}$ compared the F intake during infancy of nine-yearolds with and without fluorosis and reported a median (25th and 75 th percentiles) of $0.440(0.185,0.694)$ and $0.276(0.135$, $0.600) \mathrm{mg} / \mathrm{d}$, respectively. In view of the reported overlap in $\mathrm{F}$ intake of groups with and without fluorosis reported in the Iowa study, the strict use of the suggested range of optimal F intake might not be an appropriate basis for endorsement of any oral health strategy which requires decision-making at a community level.

The proportion (53\%) of infants living in the fluoridated area exceeding the UL of $0.1 \mathrm{mgF} / \mathrm{kg}$ BW per $\mathrm{d}$ in the present study was higher than the values of $42 \%$ and $14 \%$ estimated for infants aged 1.5 and 12 months, respectively, living in the fluoridated area of Iowa. ${ }^{22}$ This US study estimated the combined $\mathrm{F}$ intake from water, dentifrice and supplements but did not include other potentially important sources of $\mathrm{F}$ such as

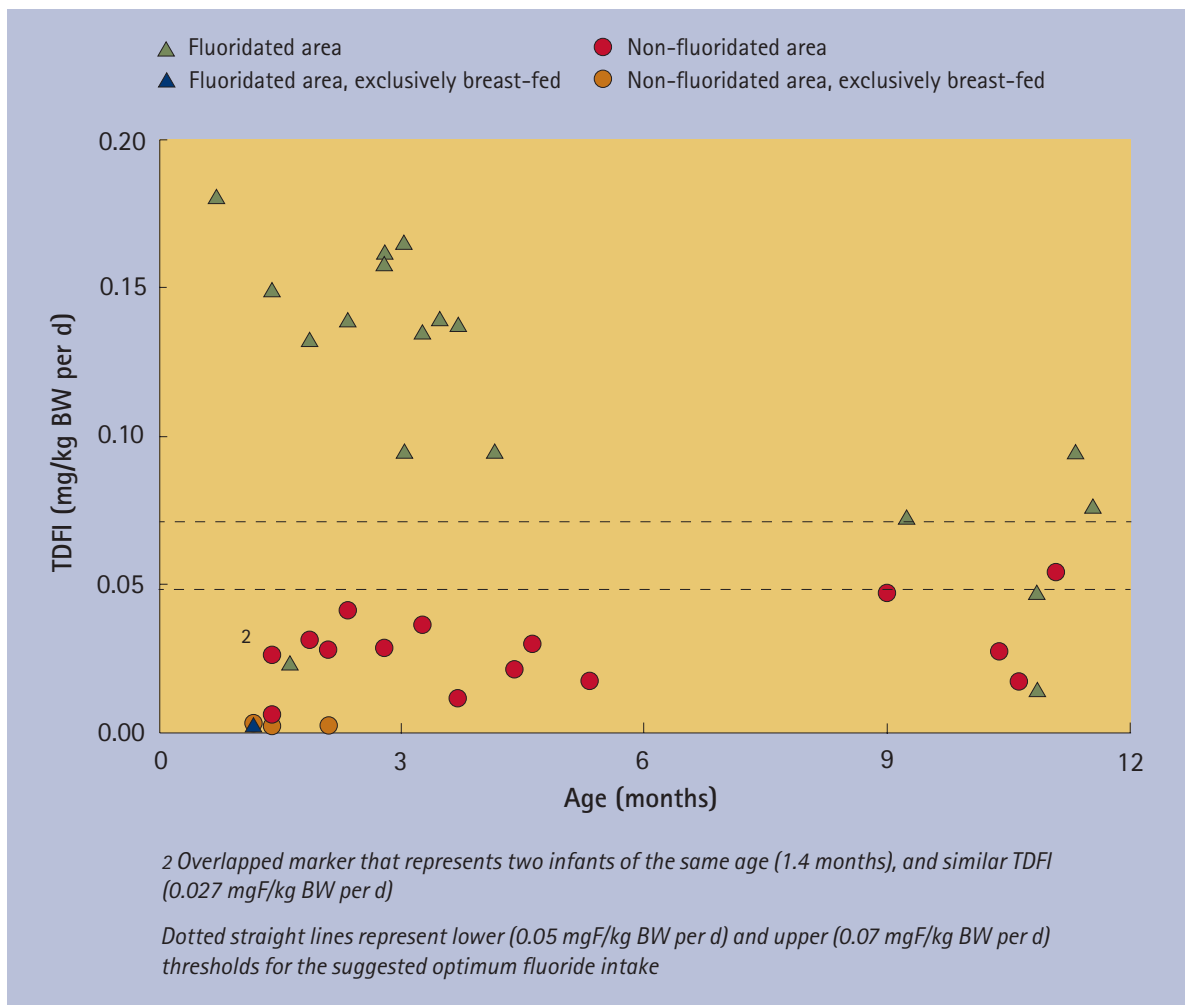

Fig.1 Association between total daily fluoride intake (TDFI) and age for infants living in fluoridated-water $(0.97 \mathrm{mg} \mathrm{F} / \mathrm{l})$ and non-fluoridated-water $(0.19 \mathrm{mg} \mathrm{F} / \mathrm{l})$ areas.

ready-to-feed food and drinks and it also used self-administered questionnaires to collect the dietary information. The differences found between the present study and the Iowa study could be due to the different methodology used for data collection as well as different dietary and oral hygiene habits of infants. Although the present study is based on a much smaller sample size, the collection of detailed information on $\mathrm{F}$ intake of infants from all important sources including total diet, toothpaste and supplements using a three-day food-diary, $\mathrm{F}$ analysis of all consumed food and drinks by infants and individual interviews with parents does provide a thorough inclusive insight into the primary $\mathrm{F}$ sources in this age group.

In conclusion, this study showed that diet was the main source of $F$ intake for infants. The study also showed no weaned infant (less than six months of age) had a TDFI of more than the UL of $0.1 \mathrm{mg} \mathrm{F} /$ $\mathrm{kg}$ BW per d; whereas more than half of non-weaned formula-fed infants exceeded the UL, which may increase their risk of developing dental fluorosis. On the other hand, almost all infants living in a non-fluoridated area received less than optimal $\mathrm{F}$ exposure to help prevent dental caries.

The prevalence of dental caries in young children in the UK highlights the need for primary prevention programmes where community-based fluoridation schemes are scarce, as a key strategy for reducing caries experience in populations. This study confirms that an estimation of TDFI at both an individual and community level is very important when recommendations for $F$ use are being considered with the goals of maximising dental caries prevention while minimising risk of dental fluorosis.

The present study was funded by a grant from the Organix Foundation, which was disclosed to the study participants. The authors report no conflicts of interest. The views expressed in this paper are those of the authors and not those of the funding body. All authors read and approved the final manuscript. AM and FVZ designed the research and drafted the manuscript. GW collected the information and samples. GW and FVZ analysed the data. PJM was involved in conceptualisation of the research and in manuscript drafting.

1. Featherstone J D. Prevention and reversal of dental caries: role of low level fluoride. Community Dent Oral Epidemiol 1999; 27: 31-40.

2. Bardsen A. 'Risk periods' associated with the development of dental fluorosis in maxillary permanent central incisors: a meta-analysis. Acta Odontol Scand 1999; 57: 247-256.

3. Evans R W, Darvell B W. Refining the estimate of the critical period for susceptibility to enamel fluorosis in human maxillary central incisors. J Public Health Dent 1995; 55: 238-249.

4. Levy S M, Hillis S L, Warren J J et al. Primary tooth fluorosis and fluoride intake during the first year of life. Community Dent Oral Epidemiol 2002; 30: 286-295.

5. Warren J J, Levy S M, Kanellis M J. Prevalence of dental fluorosis in primary dentition. J Public Health Dent 2001; 61: 87-91.

6. Institute of Medicine. Dietary reference intakes for calcium, magnesium, vitamin D, and fluoride. Washington DC: National Academy Press, 1997.

7. Walton J L, Messer L B. Dental caries and fluorosis in breast-fed and bottled-fed children. Caries Res 1981; 15: 124-137.

8. Fomon S J, Ekstrand J. Fluoride intake by infants. 
J Public Health Dent 1999; 59: 229-234.

9. Levy S M, Broffitt B, Marshall T A, EichenbergerGilmore J M, Warren J J. Associations between fluorosis of permanent incisors and fluoride intake from infant formula, other dietary sources and dentifrice during early childhood. J Am Dent Assoc 2010; 141: 1190-1201.

10. Wiatrowski E, Kramer L, Osis D, Spencer H. Dietary fluoride intake of infants. Paediatrics 1975; 55: 517-522.

11. Singer $L$, Ophaug R. Total fluoride intake of infants. Paediatrics 1979; 63: 460-466.

12. Dabeka R, McKenzie A, Conacher $H$, Kirkpatrick D C. Determination of fluoride in Canadian infant food and calculation of fluoride intakes by infants. Can J Public Health 1982; 73: 188-191.

13. Cressey P. Dietary fluoride intake for fully formula fed infants in New Zealand: impact of formula and water fluoride. J Public Health Dent 2010; 70: 285-291.

14. Zohoori FV, Moynihan P J, Omid N, Abuhaloob L, Maguire A. Impact of water fluoride concentration on the fluoride content of infant foods and drinks requiring preparation with liquids before feeding. Community Dent Oral Epidemiol 2012; 40: 432-440.

15. Maguire A, Omid N, Abuhaloob L, Moynihan P J, Zohoori FV. Fluoride content of Ready-to-Feed (RTF) infant food and drinks in the UK. Community Dent Oral Epidemiol 2012; 40: 26-36.
16. Maguire A, Zohouri FV, Hindmarch P N, Hatts J, Moynihan P J. Fluoride intake and urinary excretion in 6-to 7-year-old children living in optimally, suboptimally and non-fluoridated areas. Community Dent Oral Epidemiol 2007; 35: 479-488.

17. Butte N F. Energy requirements of infants. Public Health Nutr 2005; 8: 953-967.

18. Scientific Committee on Food. Report of the Scientific Committee on Food on the revision of essential requirements of infant formulae and follow-on formulae. Belgium: European Commission Health and Consumer Protection Directorategeneral, 2003. Online report available at http:/l ec.europa.eu/food/fs/sc/scf/out199_en.pdf (accessed October 2013).

19. Taves D R. Separation of fluoride by rapid diffusion using hexamethyldisiloxane. Talanta 1968. 15: 969-974.

20. Martínez-Mier E A, Cury J A, Heilman J R et al. Development of gold standard ion-selective electrode-based methods for fluoride analysis. Caries Res 2011; 45: 3-12.

21. Agostoni $C_{\text {, Decsi }}$, Fewtrell $\mathrm{M}$ et al. Complementary feeding: a commentary by the ESPGHAN Committee on Nutrition. J Paediatr Gastroenterol Nutr 2008; 46: 99-110.

22. Levy S M, Warren J J, Davis C S, Kirchner H L, Kanellis M J, Wefel J S. Patterns of fluoride intake from birth to 36 months. J Public Health Dent 2001; 61: 70-77.
23. Anderson W A, Pratt I, Ryan M R, Flynn A. A probabilistic estimation of fluoride intake by infants up to the age of 4 months from infant formula reconstituted with tap water in the fluoridated regions of Ireland. Caries Res 2004; 38: 421-429.

24. Rankin S J, Levy S M, Warren J J, Gilmore J E, Broffitt B. Fluoride content of solid foods impacts daily intake. J Public Health Dent 2012; 72: 128-134.

25. Pitts N B, Boyles J, Nugent Z J, Thomas N, Pine C M. The dental caries experience of 5-year-old children in Great Britain (2005/6). Surveys coordinated by the British Association for the study of community dentistry. Community Dent Health 2007; 24: 59-63.

26. Pitts N B, Boyles J, Nugent Z J, Thomas N, Pine C M The dental caries experience of 11-year-old children in Great Britain. Surveys coordinated by the British Association for the Study of Community Dentistry in 2004/2005. Community Dent Health 2006; 23: 44-57.

27. McGrady M, Ellwood R, Maguire A, Goodwin M, Boothman N, Pretty I A. The association between social deprivation and the prevalence and severity of dental caries and fluorosis in populations with and without water fluoridation. BMC Public Health 2012; 12: $11-22$.

28. Cattaneo A, Burmaz T, Arendt M et al. Protection, promotion and support of breast-feeding in Europe: progress from 2002 to 2007. Public Health Nutr 2010; 13: 751-759 